\title{
Estimation of Occupancy, Breeding Success, and Abundance of Golden Eagles (Aquila chrysaetos) in the Diablo Range, California, 2014
}

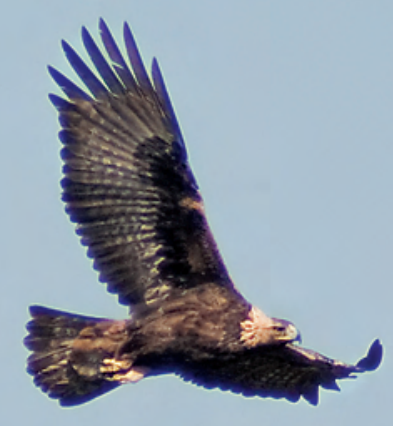

Open-File Report 2015-1039

U.S. Department of the Interior U.S. Geological Survey 
Cover: An adult golden eagle flying through the Altamont Pass Wind Resource Area, California. Photograph taken by Patrick Kolar in 2014 and used with permission. 
Estimation of Occupancy, Breeding Success, and Abundance of Golden Eagles (Aquila chrysaetos) in the Diablo Range, California, 2014

By J. David Wiens, Patrick S. Kolar, Mark R. Fuller, W. Grainger Hunt, and Teresa Hunt

Open-File Report 2015-1039

U.S. Department of the Interior

U.S. Geological Survey 


\section{U.S. Department of the Interior \\ SALLY JEWELL, Secretary}

\section{U.S. Geological Survey \\ Suzette M. Kimball, Acting Director}

U.S. Geological Survey, Reston, Virginia: 2015

For more information on the USGS—-the Federal source for science about the Earth,

its natural and living resources, natural hazards, and the environment-visit

http://www.usgs.gov or call 1-888-ASK-USGS (1-888-275-8747)

For an overview of USGS information products, including maps, imagery, and publications, visit http://www.usgs.gov/pubprod

Any use of trade, firm, or product names is for descriptive purposes only and does not imply endorsement by the U.S. Government.

Although this information product, for the most part, is in the public domain, it also may contain copyrighted materials as noted in the text. Permission to reproduce copyrighted items must be secured from the copyright owner.

\section{Suggested citation:}

Wiens, J.D., Kolar, P.S., Fuller, M.R., Hunt, W.G., and Hunt, Teresa, 2015, Estimation of occupancy, breeding success, and predicted abundance of golden eagles (Aquila chrysaetos) in the Diablo Range, California, 2014: U.S. Geological Survey Open-File Report 2015-1039, 23 p., http://dx.doi.org/10.3133/ofr20151039.

ISSN 2331-1258 (online) 


\section{Contents}

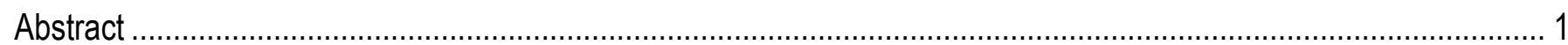

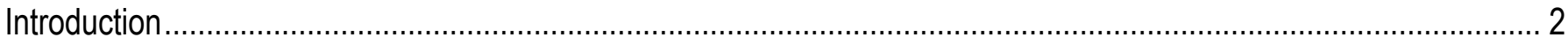

Study Area

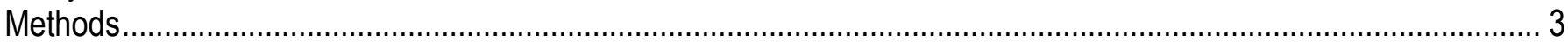

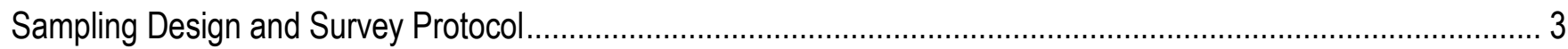

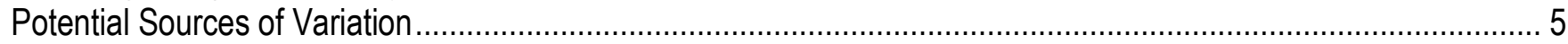

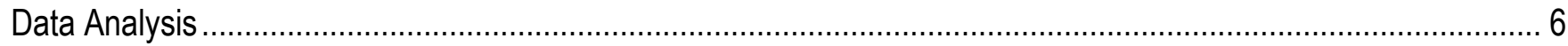

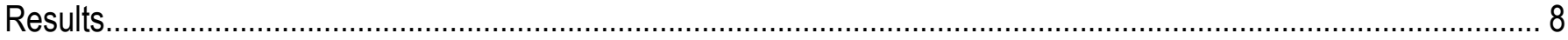

Detection and Breeding Classification of Territorial Pairs ......................................................................... 9

Probability of Occupancy and Successful Reproduction ...............................................................................11

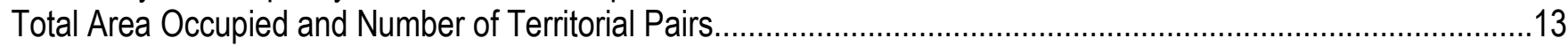

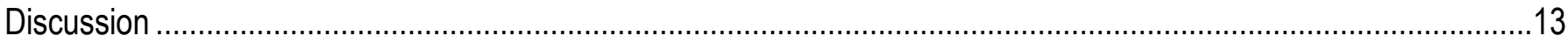

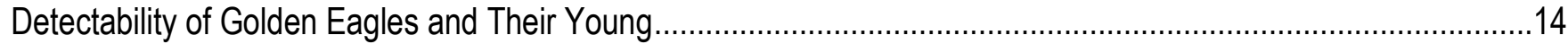

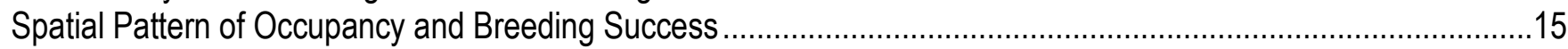

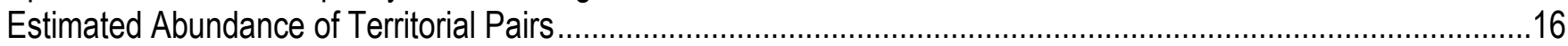

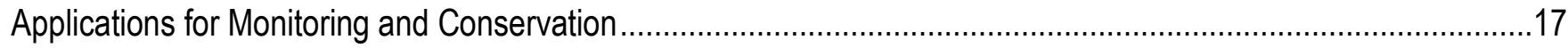

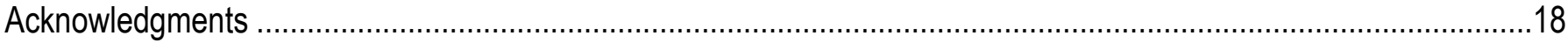

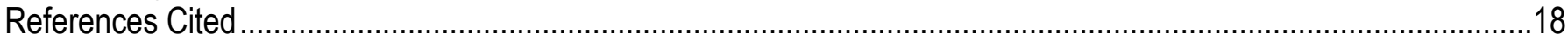

Appendix A. A priori Models Used to Characterize Variation in Detection, Occupancy, and Successful

Reproduction of Golden Eagles in the Diablo Range, California, 2014............................................................21

Appendix B. Multistate Occupancy Detection Histories of 133 Sample Sites Searched Repeatedly for

Evidence of Occupancy and Successful Reproduction by Territorial Pairs of Golden Eagles in the

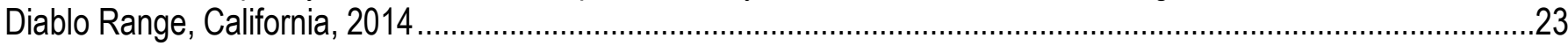

\section{Figures}

Figure 1. Map showing Diablo Range study area of west-central California and distribution of 133 randomly selected survey plots (1,385-hectare hexagons highlighted in yellow) that were repeatedly searched for evidence of occupancy and breeding success of golden eagles in 2014.

Figure 2. Graphs showing seasonal change in probability of $(\mathrm{A})$ detecting 1 or more territorial pairs of golden eagles in the Diablo Range, California, with and without historical data available on locations of previously used nests and activity centers, and (B) misclassifying a site with successful reproduction as nonbreeding given the site was occupied in 2014

Figure 3. Graphs showing probabilities of occupancy $\left(\psi^{1}\right)$ and successful reproduction $\left(\psi^{2}\right)$ of territorial pairs of golden eagles as a function of vegetation cover and terrain ruggedness in the Diablo Range, California, 2014

Figure 4. Maps showing estimated spatial pattern of $(A)$ occupancy $\left(\psi^{1}\right)$, and (B) occupancy with successful reproduction ( $\left.\psi_{\text {(breeding) }}\right)$ for territorial pairs of golden eagles in the Diablo Range study area, California, 2014. 


\section{Tables}

Table 1. Survey effort and detections of golden eagles and their young during multistate occupancy surveys conducted in the Diablo Range, California, 2014.

Table 2. Ranking of single-season multistate occupancy models used to characterize variation in the probability of occupancy $\left(\psi^{1}\right)$, breeding success $\left(\psi^{2}\right)$, detection $(p)$, and breeding classification $(\delta)$ for territorial pairs of golden eagles in the Diablo Range, California, 2014.

\section{Conversion Factors and Datum}

\section{Conversion Factors}

SI to Inch/Pound

\begin{tabular}{lcl}
\hline & Multiply & \\
\hline & Length & To obtain \\
\hline meter $(\mathrm{m})$ & 3.281 & foot $(\mathrm{ft})$ \\
kilometer $(\mathrm{km})$ & 0.6214 & mile $(\mathrm{mi})$ \\
\hline & Area & \\
\hline hectare (ha) & 2.471 & acre \\
hectare (ha) & 0.003861 & square mile $\left(\mathrm{mi}^{2}\right)$ \\
square kilometer $\left(\mathrm{km}^{2}\right)$ & 247.1 & acre \\
square kilometer $\left(\mathrm{km}^{2}\right)$ & 0.3861 & square mile $\left(\mathrm{mi}^{2}\right)$ \\
\hline
\end{tabular}

\section{Datum}

Horizontal coordinate information is referenced to the North American Datum of 1983 (NAD 83). 


\title{
Estimation of Occupancy, Breeding Success, and Abundance of Golden Eagles (Aquila chrysaetos) in the Diablo Range, California, 2014
}

\author{
By J. David Wiens ${ }^{1}$, Patrick S. Kolar², Mark R. Fuller ${ }^{1}$, W. Grainger Hunt², and Teresa Hunt ${ }^{2}$
}

\begin{abstract}
We used a multistate occupancy sampling design to estimate occupancy, breeding success, and abundance of territorial pairs of golden eagles (Aquila chrysaetos) in the Diablo Range, California, in 2014. This method uses the spatial pattern of detections and non-detections over repeated visits to survey sites to estimate probabilities of occupancy and successful reproduction while accounting for imperfect detection of golden eagles and their young during surveys. The estimated probability of detecting territorial pairs of golden eagles and their young was less than 1 and varied with time of the breeding season, as did the probability of correctly classifying a pair's breeding status. Imperfect detection and breeding classification led to a sizeable difference between the uncorrected, naïve estimate of the proportion of occupied sites where successful reproduction was observed (0.20) and the model-based estimate $(0.30)$. The analysis further indicated a relatively high overall probability of landscape occupancy by pairs of golden eagles $(0.67$, standard error $=0.06)$, but that areas with the greatest occupancy and reproductive potential were patchily distributed. We documented a total of 138 territorial pairs of golden eagles during surveys completed in the 2014 breeding season, which represented about one-half of the 280 pairs we estimated to occur in the broader 5,169-square kilometer region sampled. The study results emphasize the importance of accounting for imperfect detection and spatial heterogeneity in studies of site occupancy, breeding success, and abundance of golden eagles.
\end{abstract}

\footnotetext{
${ }^{1}$ U.S. Geological Survey.

${ }^{2}$ The Peregrine Fund, Inc.
} 


\section{Introduction}

The northern Diablo Range of west-central California is hypothesized to support one of the densest known breeding populations of golden eagles (Aquila chrysaetos) in North America (Hunt, 2002; Hunt and Hunt, 2006, 2013). This region includes the Altamont Pass Wind Resource Area (APWRA), where previous reports suggest that about 65 golden eagles were killed annually by collisions with wind turbines during 1998-2002 (Smallwood and Thelander, 2008). Concerns about whether the local breeding population of golden eagles surrounding the APWRA could sustain such mortality prompted a demographic investigation (Hunt and others, 1998; Hunt, 2002; Hunt and Hunt, 2013). One component of that study used radiotelemetry to examine life-stage-specific movements and survival of golden eagles in an approximately 7,000$\mathrm{km}^{2}$ aerial survey region encompassing APWRA, while another component focused on determining annual occupancy of nesting territories and reproduction within $30 \mathrm{~km}$ of APWRA. Tracking data indicated that many individuals captured near the wind-energy facility remained year-round residents of the broader region of the Diablo Range, and that collisions with wind turbines was the leading cause of death (Hunt and others, 1998; Hunt, 2002). Estimates of survival and reproduction were used to determine the potential rate of population change and total number of territorial pairs required to sustain 50 turbine blade-strike fatalities annually (about 165 pairs; Hunt and others, 1998; Hunt, 2002; Hunt and Hunt, 2006). Golden eagles have not been systematically surveyed in the broader region to which these demographic estimates apply, thus the approximate number of breeding pairs that actually occupy this remote and varied landscape remains unknown.

Monitoring occupancy and reproduction of golden eagles at broad spatial scales can be logistically challenging and expensive. Recent advances in survey design and interpretation of distributional data have made species-level monitoring at broad spatial scales considerably more feasible and cost effective than in the past (Noon and others, 2012). Sampling designs associated with site occupancy models have been shown to be particularly useful in investigating the dynamics of territorial species occurrence and evaluating how landscape features or human land use might influence those dynamics (MacKenzie and others, 2006; Martin and others, 2009; Wiens and others, 2011). Individuals of many species may be difficult to detect, depending on physiographic conditions or period of the breeding cycle, so strong inference for site occupancy studies requires accounting for imperfect detection (that is, the inability of researchers to detect a species at a sample site with 100 percent certainty). Failing to account for imperfect detection can lead to inaccurate estimates of population parameters, such as the proportion of sites that are occupied, the proportion of sites with successful reproduction, or abundance (MacKenzie and others, 2006, 2009; Nichols and others, 2007). Extensions of basic site-occupancy models consider multiple biologically relevant states, such as breeding or nonbreeding, which increase the applicability of these methods to address conservation of species of special concern. In the case of golden eagles, this approach can be used to estimate, map, and analyze spatial patterns of occupancy and reproduction over a range of spatial scales. Such information can help identify areas for conservation prioritization - a key requirement for conservation policy that aims to maximize breeding success and maintain stable or increasing breeding populations of golden eagles (U.S. Fish and Wildlife Service, 2013). 
We used a multistate occupancy study design (Nichols and others, 2007; MacKenzie and others, 2009) to investigate detection, occupancy, and breeding success for the territorial population of golden eagles in the northern Diablo Range encompassing APWRA. We also explored how occupancy data could be used to infer abundance of territorial pairs in the Diablo Range study area. The surveys included all age classes of golden eagles (that is, juveniles, subadults, breeders, and nonbreeding adults), but the focus here is on estimation of detection, occupancy, and reproduction of golden eagles in 2014. Specific objectives of the study were to:

1. Examine potential sources of variation in the probability of detection, occupancy, and reproduction of territorial pairs;

2. Use estimates of landscape occupancy to estimate the total number of pairs in the Diablo Range study area; and

3. Provide recommendations to improve strategies for monitoring breeding and nonbreeding golden eagles exposed to renewable energy development.

Here, we report results from an analysis of survey data collected during the 2014 breeding season.

\section{Study Area}

The $5,170-\mathrm{km}^{2}$ study area was located in the Diablo Range of west-central California (fig. 1). We delineated this area based on movements of golden eagles radio-marked near the APWRA during 1994-2000 (Hunt, 2002). The study area ranged in elevation from 0 to $1,333 \mathrm{~m}$ above sea level and was dominated by chaparral and California oak-woodland communities, with stands of conifer forest appearing at elevations greater than 1,200 $\mathrm{m}$ above sea level. The northern part of the study area was mostly grassland with occasional rocky outcroppings and widely scattered stands of oak (Quercus spp.), eucalyptus (Eucalyptus spp.), digger pine (Pinus sabiniana), bigcone pine (Pinus coulteri), and California buckeye (Aesculus californica). Grasslands with scattered stands of oak (oak savannah) descend to the agricultural flatlands of the San Joaquin Valley to the east, and the study area was bounded to the west and southwest by highly developed urban areas extending from Berkeley and the San Francisco Bay southward to San Jose. Vegetation types were more diverse in the central part of the study area, which included a high density of oak woodlands interspersed with chaparral, sage-scrub, and open grassland. Land use in the study area included private ranchlands with livestock grazing, in addition to State and county lands characterized by varying levels of grazing and recreational use. The APWRA was located in the northeastern quadrant of the study area (fig. 1). We delineate this 17,345 ha area using a minimum convex polygon estimated from 5,425 windturbine locations (http://www.altamontsrc.org/alt_amp.html, accessed February 23, 2013). Further details on APWRA are provided by Hunt (2002) and Smallwood and Thelander (2008).

\section{Methods}

\section{Sampling Design and Survey Protocol}

The study area included all areas in public or private ownership potentially occupied by territorial pairs of golden eagles. We excluded densely populated areas and agricultural fields of the San Joaquin Valley from the sampling scheme because golden eagles were rarely observed in these landscapes (Hunt, 2002, p. 24-25). Surveys could not be performed in all areas potentially 


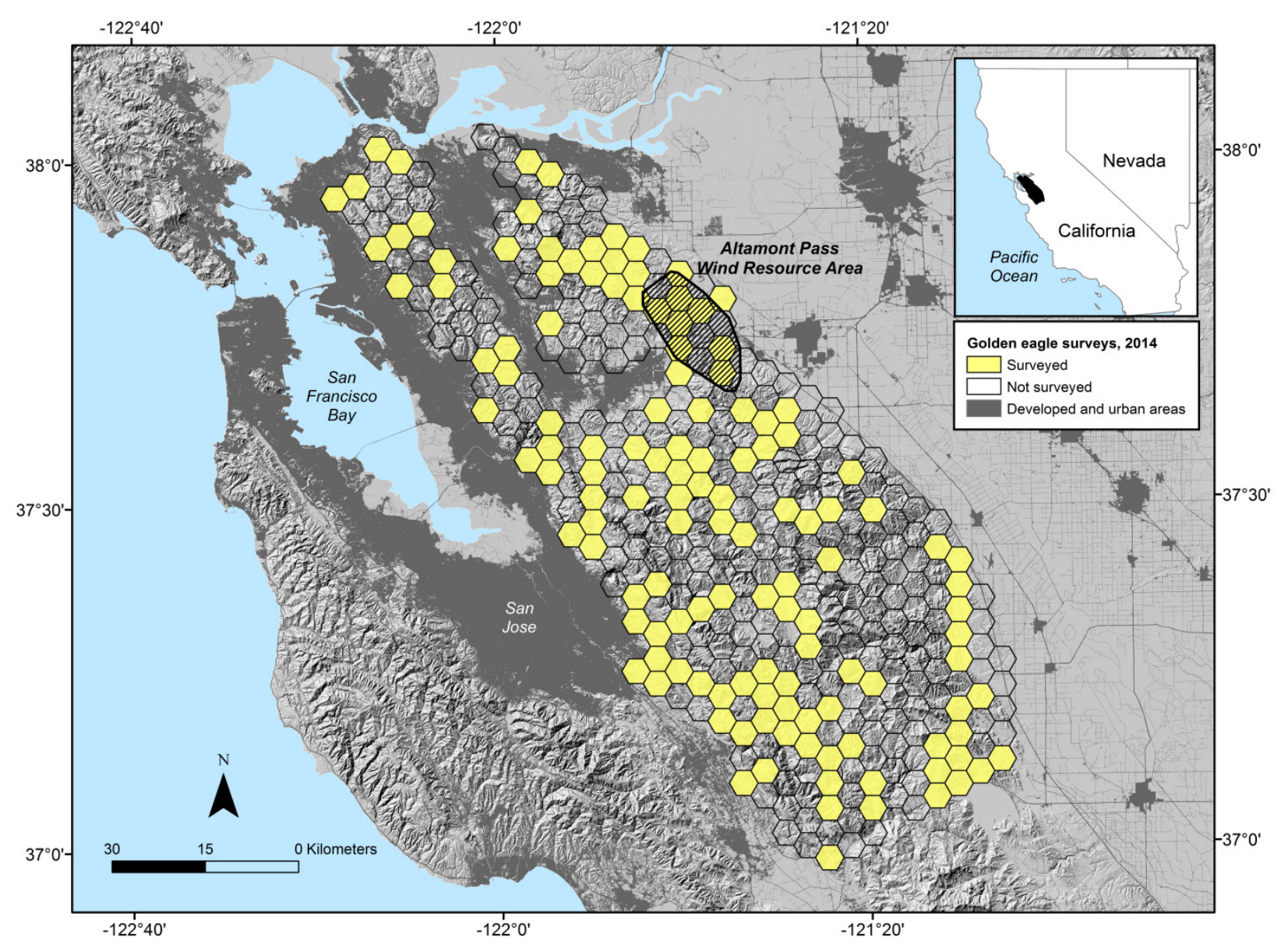

Figure 1. Map showing Diablo Range study area of west-central California and distribution of 133 randomly selected survey plots (1,385-hectare hexagons highlighted in yellow) that were repeatedly searched for evidence of occupancy and breeding success of golden eagles in 2014.

occupied by eagles because of budget constraints, logistical considerations, and limited access to private lands. As a consequence, we used a probabilistic sampling approach to infer estimates of occupancy, reproduction, and number of territorial pairs of golden eagles. Specifically, we used a multistate occupancy sampling framework (Nichols and others, 2007; MacKenzie and others, 2009), where randomly selected sites were surveyed repeatedly and classified as unoccupied (state $=0$ ), occupied by one or more pairs with no production of young (state $=1$ ), or occupied with successful reproduction ( state $=2$ ). Areas targeted for repeated surveys of golden eagles were selected randomly from a grid of 373 equal-sized $(1,385 \mathrm{ha})$ hexagonal cells overlaid on the study area (total area $=516,844$ ha; fig. 1 ). The size of each survey hexagon corresponded to the estimated mean size of the annual core-use area for territorial golden eagles radio-marked in the study area during 1994-1999 (about 1,385 ha; Wiens and Hunt, U.S. Geological Survey, unpub. data, 2012). Thus, in the sampling design, a "site" was defined as a 1,385 -ha randomly placed survey hexagon that had the potential to be occupied by 1 or more pairs of golden eagles during the breeding season. 
We followed general recommendations by Driscoll (2010) and Pagel and others (2010) for determining territory occupancy and reproduction of golden eagles during ground-based surveys. We partitioned surveys using four developmental stages of the breeding season, based on mean dates for stages in the breeding cycle of golden eagles in our study area (Hunt and others, 1996; Hunt, 2002): courtship (January 1-February 28), incubation (March 1-April 30), nestling (May 1-June 15), and the fledging period (June 16-July 30). Each two-month interval represented a survey occasion in our occupancy analysis. On each survey, observers established 1-4 observation points on selected ridges and hilltops to provide complete coverage of the focal sample site. Observers then searched for evidence of occupancy and reproduction by territorial pairs for up to a 4-hr observation period. The goal of each survey was to characterize the focal sample site as being in one of three possible observation states: (1) no territorial pair of golden eagles detected; (2) territorial pair detected but no evidence of nesting observed; or (3) territorial pair detected with evidence of successful reproduction found (1 or more fledgling produced). Some sites required more than one survey spaced less than 5 days apart to achieve complete coverage. When possible, eagles were classified as juveniles, subadults, or adults based on visible plumage characteristics (Bloom and Clark, 2001). We considered a sample site to be occupied by a territorial pair if we observed (1) a male and female copulating, undulating, or perching together, or attacking intruders; (2) an incubating eagle in a nest or a female with a brood patch; or (3) nestlings or fledglings in or near a nest (Steenhof and others, 1997; Kochert and others, 2002). We attributed detections of territorial pairs to sample sites by mapping activity centers of pairs (that is, a nest with young, focal area of copulations, territorial displays, fledged young, perches). Sample sites were surveyed with pair detections during mid-June to late July to determine number of young fledged, after most nestlings were greater than 80 percent of average fledging age (51 days old; Kochert and others, 2002). A site was classified with successful breeding if nestlings or fledglings of this age were observed (Steenhof and Newton, 2007).

\section{Potential Sources of Variation}

Anticipating heterogeneity in parameter estimates and minimizing its effects - through study design and by collecting data on relevant covariates to model existing variation - is essential for good performance of occupancy models (MacKenzie and others, 2006). Consequently, we developed a small set of a priori models to explore potential site- and surveyspecific sources of variation in probability of detection, occupancy, and reproduction of golden eagles. We anticipated spatial heterogeneity in the probability of detection because some of the sample sites $(n=33)$ overlapped areas previously surveyed by Hunt and Hunt (2013) and had a wealth of historical information available on locations of previously used activity centers, whereas other sites $(n=100)$ had never been surveyed and had no historical information on golden eagles. Observers often used historical information as a basis to locate eagles, so we anticipated that probability of detection may have been greater for sites where such information was available. To account for this source of heterogeneity in detection, we used a spatial covariate that allowed detection rates to vary between sample sites with and without historical information on golden eagles (for example, the covariate was 1 if historical data were available for a site and 0 otherwise). We also predicted that the amount of forest cover could have a negative influence on the probability of detection because golden eagles in the study area nested almost exclusively in trees, which often obscured observations of adults and young during surveys, especially at sites with more contiguous patches of oak and conifer forest. 
We hypothesized that landscape features including vegetation cover type and terrain could influence occupancy and reproduction of golden eagles because prey-detection and hunting success typically are associated with rugged, open landscapes (Marzluff and others, 1997; Carrete and others, 2000; McIntyre and others, 2006). Accordingly, we used the 1996 classification of the National Oceanic and Atmospheric Administration's Coastal Change Analysis Program (C-CAP) regional land cover to characterize the distribution of primary vegetation types in our study area (National Oceanic and Atmospheric Administration, 2010). The map included 29 categories of land cover (21 of which occurred within the study area) and was produced for the Pacific coastal region of California using 30-m resolution Landsat Thematic Mapper and Landsat Enhanced Thematic Mapper satellite imagery. Extensive field sampling, validation, and standard quality-control review procedures were used in developing the map (National Oceanic and Atmospheric Administration, 2010). For our analysis, we combined existing land-cover types into three general categories that we hypothesized would represent important sources of spatial variation in the study area-open grassland, scrub/shrub cover, and evergreen and deciduous forest cover. To evaluate how terrain features might influence landscape occupancy of golden eagles, we used $\operatorname{ArcGIS}^{\mathrm{TM}}$ (v. 10.1) and a 10-m resolution digital elevation model (DEM) to estimate mean terrain ruggedness (TRI) for each sample site in the study area (Riley and others, 1999). Terrain ruggedness was calculated as the difference between the elevation value of each 10-m cell of the DEM and the mean of the 8-cell neighborhood surrounding the focal cell. We considered TRI as a measure of terrain heterogeneity among sample sites, where larger values indicated greater heterogeneity.

\section{Data Analysis}

Detection, Occupancy, and Reproduction of Territorial Pairs. - We used singleseason multistate occupancy models (Nichols and others, 2007) in Program MARK (White and Burnham, 1999) to estimate detectability $(p)$, occupancy $\left(\psi^{1}\right)$, and breeding state of golden eagles $\left(\psi^{2}\right)$, where :

$\psi_{i}^{1}$ was the probability that sample site $i$ is occupied by 1 or more territorial pairs of golden eagles, regardless of reproductive state (state 1);

$\psi_{i}^{2}$ was the conditional probability that young occurred, given that sample site $i$ is occupied by a territorial pair (state 2);

$\psi_{i \text { (breeding) }}$ was the unconditional probability that sample site $i$ is occupied with breeding, regardless of occupancy state $\left(=\psi_{i}^{1} * \psi_{i}^{2}\right)$;

$p_{i t}^{1}$ was the probability that occupancy is detected for site $i$, survey occasion $t$, given that true state $=1$;

$p_{i t}^{2}$ was the probability that occupancy is detected for site $i$, survey occasion $t$, given that true state $=2$; and

$\delta_{\text {it }}$ was the probability that evidence of successful reproduction is found, given detection of occupancy at site $i$ on occasion $t$, and true state $=2$. 
Primary assumptions of the multistate occupancy analysis were that (1) occupancy status of sites (1,385-ha sample hexagons) did not change during the breeding season, and (2) detection histories among sample sites were independent (Nichols and others, 2007; MacKenzie and others, 2009). We developed and tested models using a sequential approach to model selection (appendix A). We began by developing a set of 10 a priori models where detection probabilities $(p)$ were modeled as constant over occupancy states and survey occasions (that is, breeding stages), varying between occupancy states but constant over survey occasions, constant between occupancy states but varying with survey occasion, and varying with occupancy state and survey occasion. Classification probabilities $(\delta)$ were modeled as either constant over survey occasions or time-dependent. We fixed $\delta_{1}=0$ in all models because it was not possible to observe successful reproduction during the first survey occasion (courtship period; January-February). During this initial analysis, the two occupancy parameters $\left(\psi_{i}^{1}, \psi_{i}^{2}\right)$ were allowed to vary as a function of grassland and terrain ruggedness covariates. Our intention was to use the most general model for $\psi_{i}^{1}$ and $\psi_{i}^{2}$ while identifying the best model structure for detection and classification parameters. In the second step of the analysis, we fixed detection $(p)$ and classification $(\delta)$ to the best model structure from the previous analysis step and evaluated the relative influence of spatial covariates on occupancy $\left(\psi_{i}^{1}\right)$ and reproduction $\left(\psi_{i}^{2}\right)$. We compared all models to an intercept-only model, which represented the null hypothesis that probability of detection, occupancy, and reproduction probabilities remained spatially constant.

We used a deviance-based goodness-of-fit statistic to compute the quasi-likelihoodadjusted, small-sample Akaike's Information Criterion $\left(Q \mathrm{AIC}_{c}\right)$ for model selection (Burnham and Anderson, 2002; Nichols and others, 2007). The deviance-based variance inflation factor $(\hat{c})$ estimated for our survey data was 1.60 , which indicated minor lack of fit of the most general model. Lack of fit was not severe, and was anticipated because detections of the same territorial pairs in adjacent sample sites could lead to a minor lack of independence among detection histories. The use of $\hat{c}$, therefore, was biologically justified and provided a means to adjust model selection and variance estimation accordingly (Burnham and Anderson, 2002; Mackenzie and others, 2006). We ranked a total of 24 candidate models using $Q \mathrm{AIC}_{c}$; the model with the lowest $Q \mathrm{AIC}_{\mathrm{c}}$ value was selected as providing the best description of the survey data. We evaluated strength of evidence for each model using $\triangle Q \mathrm{AIC}_{c}$ and $Q \mathrm{AIC}_{c}$ weights, and calculated modelaveraged parameter estimates and unconditional variances from top-model sets (Burnham and Anderson, 2002). We further evaluated the effect of covariates by evaluating 95-percent confidence intervals $(95 \% \mathrm{CI})$ of slope coefficients $(\beta)$, based on the degree to which intervals overlapped zero. 
Estimation of Total Area Occupied and Number of Territorial Pairs. - We used our top multistate occupancy model to infer estimates of occupancy and reproduction across the entire study area. For sample sites that were not surveyed, we estimated unconditional occupancy and reproduction (that is, the probability that site $i$ is occupied based on covariate values associated with the site; MacKenzie and others, 2006). For surveyed sites where 1 or more pairs of golden eagles were seen, the probability of occupancy was set to 1. For surveyed sites where pairs of golden eagles were not seen, conditional estimates of occupancy were calculated using the site's detection history and associated covariate values (Rich and others, 2013). To estimate the total area occupied by pairs of golden eagles in the study area, we multiplied site-specific estimates of occupancy by the respective size of each sample site $(1,385 \mathrm{ha})$, and summed these values across all available sites $(n=373)$. This procedure was similar to that used to estimate annual numbers of gray wolf (Canis lupus) territories in Montana (Rich and others, 2013), which assumed minimal overlap among occupied territories and minimal unoccupied space between territories. To estimate the total number of territorial pairs, we divided our estimate of the total area occupied by the estimated mean territory size for golden eagles in the study area (1,385 ha). We used this estimation procedure because it was repeatable, it accounted for spatial variation in pair occupancy, and it dealt with uncertainties associated with imperfect detection probabilities. Confidence intervals for total area occupied and number of territorial pairs were obtained using a parametric bootstrap procedure in program MARK (White and Burnham, 2001). Here, we repeatedly simulated encounter histories for each survey site using the estimated sampling uncertainty associated with parameter estimates in the top multistate occupancy model. We then calculated total area occupied and number of pairs for each bootstrap iteration, and obtained $95 \%$ confidence intervals for these values from the resulting distribution of simulated estimates.

\section{Results}

We searched 133 sample sites over four occasions and recorded 899 detections of golden eagles_-534 (59 percent) adults, 164 (18 percent) subadults, 67 (8 percent) juveniles (first-year birds), and 134 (15 percent) golden eagles of unknown age-class. We observed 98 territorial pairs of golden eagles at 87 sample sites (table 1). Based on mapped locations of used nests and pair activity centers, 77 (88.5 percent) of the 87 sample sites were occupied by one pair of golden eagles, 9 (10.3 percent) were occupied by two pairs, and 1 (1.1 percent) was occupied by three pairs $(\bar{x}=1.13$ pairs per sample site). During surveys, we observed an additional 40 territorial pairs of golden eagles with activity centers outside the boundary of the focal survey site. Thus, we identified a total of 138 territorial pairs of golden eagles, 98 of which were located in focal sample sites and included in occupancy analyses. No golden eagles were detected in 14 (11 percent) of 133 sites surveyed, and subadults or juveniles, but no adults, were detected at 27 (20 percent) sites. 
Table 1. Survey effort and detections of golden eagles and their young during multistate occupancy surveys conducted in the Diablo Range, California, 2014.

[Breeding stages were courtship (January 1-February 28), incubation (March 1-April 30), nestling (May 1-June 15), and fledgling (June 16-July 31)]

\begin{tabular}{lcccc}
\hline $\begin{array}{c}\text { Survey occasion and } \\
\text { breeding stage }\end{array}$ & $\begin{array}{c}\text { Sites } \\
\text { surveyed }\end{array}$ & $\begin{array}{c}\text { Number of sites } \\
\text { surveyed with 1 or more } \\
\text { golden eagles detected } \\
\text { (percentage) }\end{array}$ & $\begin{array}{c}\text { Number of sites } \\
\text { surveyed with 1 or } \\
\text { more territorial pairs } \\
\text { detected (percentage) }\end{array}$ & $\begin{array}{c}\text { Number of occupied } \\
\text { sites with 1 or more } \\
\text { young produced } \\
\text { (percentage) }\end{array}$ \\
\hline 1: courtship & 111 & $95(77.5)$ & $64(57.7)$ & \\
2: incubation & 123 & $90(72.6)$ & $64(52.0)$ & $2(1.6)$ \\
3: nestling & 113 & $80(64.0)$ & $39(34.5)$ & $11(9.7)$ \\
4: fledgling & 71 & $49(76.6)$ & $20(28.2)$ & $11(15.5)$ \\
All visits combined & 133 & $119(89.5)$ & $87(65.4)$ & $17(19.5)$ \\
\hline
\end{tabular}

\section{Detection and Breeding Classification of Territorial Pairs}

Detection histories of sample sites that were surveyed at least once are shown in appendix B. Model selection results for detection and classification probabilities showed that the probability of detecting pairs of golden eagles was dependent on time of season (that is, stage of the reproductive cycle) and site-specific availability of historical data on previously used activity centers (table 2, fig. 2A). As predicted, availability of historical data during a survey had a positive effect on detection probability $(\widehat{\beta}=0.840,95 \% \mathrm{CI}=0.046-1.634)$. Models where detection probabilities differed between breeding and nonbreeding occupancy states were not well-supported $\left(\triangle Q \mathrm{AIC}_{c} \geq 5.5\right.$; table 2$)$. We found a weak negative effect of forest cover on the probability of detecting golden eagles and their young $(\widehat{\beta}=-0.629,95 \% \mathrm{CI}=-2.552-1.295)$, but the confidence interval of the beta coefficient included zero, and models with this effect received relatively weak support. The per-visit probability of misclassifying an occupied sample site with successful reproduction decreased from 0.91 for surveys conducted during the early nestling period to near 0 for surveys conducted late in the breeding season (fig. 2B). 
Table 2. Ranking of single-season multistate occupancy models used to characterize variation in the probability of occupancy $\left(\psi^{1}\right)$, breeding success $\left(\psi^{2}\right)$, detection $(p)$, and breeding classification $(\delta)$ for territorial pairs of golden eagles in the Diablo Range, California, 2014.

[Model: Time effects modeled as constant (.) or varying with survey occasion $(t)$. Spatial covariates included: sample site availability of historical data (HD), proportion of sample site with grassland, forest, or scrub cover, and terrain ruggedness (TRI). $Q \mathrm{AIC}_{c}=$ quasi-likelihood Akaike's Information Criterion for small sample size; $\triangle Q \mathrm{AIC}_{c}$ $=$ difference between the $Q \mathrm{AIC}_{c}$ value of each model and the lowest $Q \mathrm{AIC}_{c}$ model; $w_{i}=$ model $Q \mathrm{AIC}_{c}$ weight $]$

\begin{tabular}{|c|c|c|c|c|}
\hline Model & $\begin{array}{l}\text { Number of } \\
\text { parameters }\end{array}$ & QAIC $_{c}$ & $\Delta Q A I C_{c}$ & Weight, $w_{i}$ \\
\hline \multicolumn{5}{|l|}{ Probability of detection and classification } \\
\hline$\psi^{1}($ grassland $+\mathrm{TRI}) \psi^{2}\left(\right.$ grassland $\left.^{2}\right) p(t+\mathrm{HD}) \delta(t)$ & 14 & 376.9 & 0.0 & 0.63 \\
\hline$\psi^{1}($ grassland + TRI $) \psi^{2}\left(\right.$ grassland $\left.^{2}\right) p(t) \delta(t)$ & 13 & 379.0 & 2.1 & 0.22 \\
\hline$\psi^{1}($ grassland + TRI $) \psi^{2}\left(\right.$ grassland $\left.^{2}\right) p(t+$ forest $) \delta(t)$ & 14 & 381.1 & 4.2 & 0.08 \\
\hline$\psi^{1}($ grassland + TRI $) \psi^{2}\left(\right.$ grassland $\left.^{2}\right) p 1(t) p 2(t) \delta(t)$ & 17 & 382.9 & 5.9 & 0.03 \\
\hline$\psi^{1}$ (grassland + TRI) $\psi^{2}\left(\right.$ grassland $\left.^{2}\right) p 1() p .2(.) \delta(t)$ & 11 & 383.4 & 6.5 & 0.02 \\
\hline$\psi^{1}($ grassland + TRI $) \psi^{2}\left(\right.$ grassland $\left.^{2}\right) p(.) \delta(t)$ & 10 & 384.4 & 7.4 & 0.02 \\
\hline$\psi^{1}($ grassland + TRI $) \psi^{2}\left(\right.$ grassland $\left.^{2}\right) p 1(t) p 2(t) \delta()$. & 15 & 389.3 & 12.4 & 0.00 \\
\hline$\psi^{1}($ grassland + TRI $) \psi^{2}\left(\right.$ grassland $\left.^{2}\right) p(t) \delta()$. & 11 & 390.1 & 13.1 & 0.00 \\
\hline$\psi^{1}($ grassland + TRI $) \psi^{2}\left(\right.$ grassland $\left.^{2}\right) p 1() p .2(.) \delta()$. & 9 & 391.6 & 14.7 & 0.00 \\
\hline$\psi^{1}($ grassland + TRI $) \psi^{2}\left(\right.$ grassland $\left.^{2}\right) p(.) \delta()$. & 8 & 395.7 & 18.7 & 0.00 \\
\hline \multicolumn{5}{|l|}{ Probability of occupancy and reproduction } \\
\hline$\psi^{1}($ grassland $+\mathrm{TRI}) \psi^{2}(\mathrm{scrub}) p(t+\mathrm{HD}) \delta(t)$ & 13 & 371.8 & 0.0 & 0.66 \\
\hline$\psi^{1}($ grassland $+\mathrm{TRI}) \psi^{2}($ grass $) p(t+\mathrm{HD}) \delta(t)$ & 13 & 375.8 & 4.0 & 0.09 \\
\hline$\psi^{1}($ grassland + TRI $) \psi^{2}\left(\right.$ forest $\left.^{2}\right) p(t+\mathrm{HD}) \delta(t)$ & 13 & 376.6 & 4.8 & 0.06 \\
\hline$\psi^{1}($ grassland + TRI $) \psi^{2}() p.(t+\mathrm{HD}) \delta(t)$ & 12 & 376.8 & 5.0 & 0.05 \\
\hline$\psi^{1}($ grassland + TRI $) \psi^{2}\left(\right.$ grass $\left.^{2}\right) p(t+\mathrm{HD}) \delta(t)$ & 14 & 376.9 & 5.1 & 0.05 \\
\hline$\psi^{1}($ grassland $+\mathrm{TRI}) \psi^{2}$ (forest) $p(t+\mathrm{HD}) \delta(t)$ & 13 & 377.9 & 6.1 & 0.03 \\
\hline$\psi^{1}$ (grassland) $\psi^{2}() p.(t+\mathrm{HD}) \delta(t)$ & 11 & 380.6 & 8.8 & 0.01 \\
\hline$\psi^{1}($ grassland + TRI $) \psi^{2}\left(\right.$ grass $\left.^{2}\right) p(t+$ forest $) \delta(t)$ & 14 & 381.1 & 9.3 & 0.01 \\
\hline$\psi^{1}(.) \psi^{2}() p.(t+\mathrm{HD}) \delta(t)$ & 10 & 381.9 & 10.1 & 0.00 \\
\hline$\psi^{1}\left(\right.$ grassland $\left.^{2}\right) \psi^{2}() p.(t+\mathrm{HD}) \delta(t)$ & 12 & 382.5 & 10.7 & 0.00 \\
\hline$\psi^{1}$ (forest) $\psi^{2}() p.(t+\mathrm{HD}) \delta(t)$ & 11 & 382.5 & 10.7 & 0.00 \\
\hline$\psi^{1}($ forest $+\mathrm{TRI}) \psi^{2}() p.(t+\mathrm{HD}) \delta(t)$ & 12 & 382.5 & 10.7 & 0.00 \\
\hline$\psi^{1}($ grassland + TRI $) \psi^{2}\left(\operatorname{grass}^{2}\right) p 1(t) p 2(t) \delta(t)$ & 17 & 382.9 & 11.1 & 0.00 \\
\hline$\psi^{1}(\mathrm{TRI}) \psi^{2}() p.(t+\mathrm{HD}) \delta(t)$ & 11 & 384.1 & 12.3 & 0.00 \\
\hline$\psi^{1}(\mathrm{scrub}) \psi^{2}() p.(t+\mathrm{HD}) \delta(t)$ & 11 & 384.3 & 12.5 & 0.00 \\
\hline$\psi^{1}\left(\right.$ forest $\left.^{2}\right) \psi^{2}() p.(t+\mathrm{HD}) \delta(t)$ & 12 & 384.3 & 12.5 & 0.00 \\
\hline$\psi^{1}(\mathrm{scrub}+\mathrm{TRI}) \psi^{2}() p.(t+\mathrm{HD}) \delta(t)$ & 12 & 386.2 & 14.5 & 0.00 \\
\hline
\end{tabular}


A

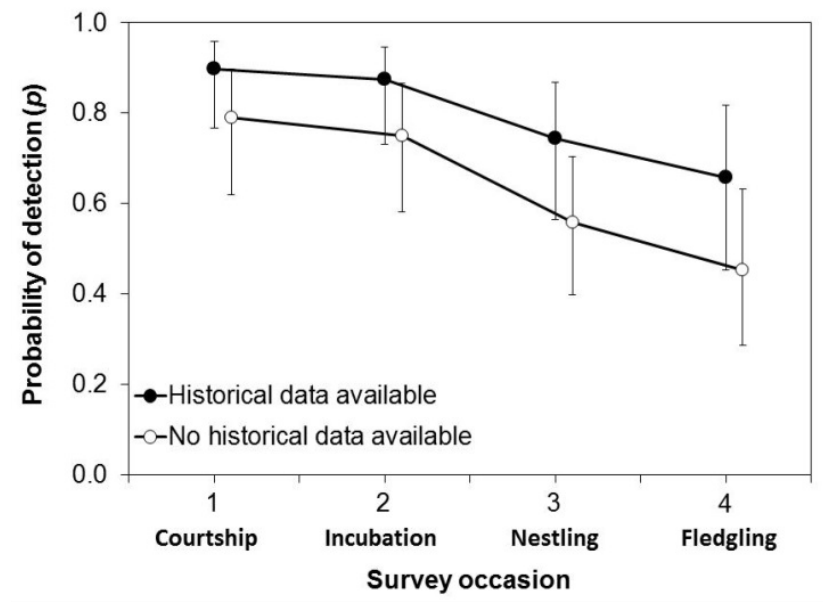

B

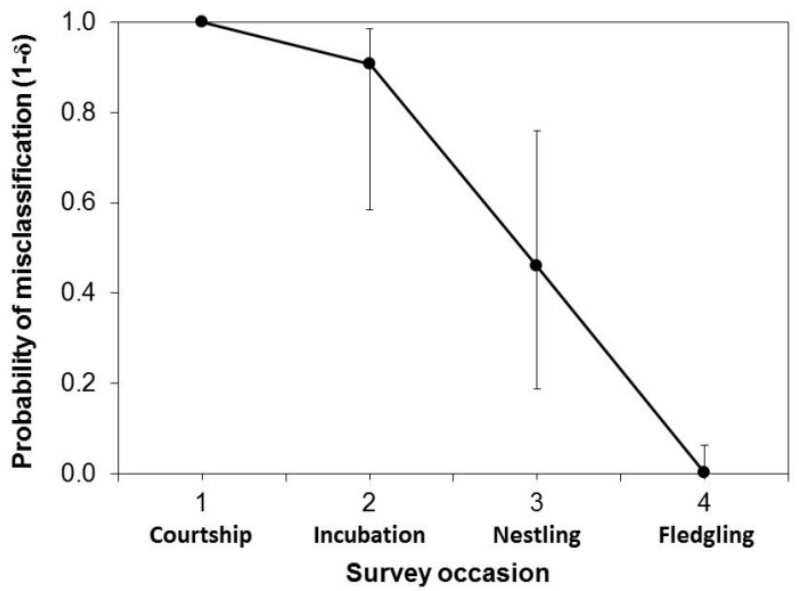

Figure 2. Graphs showing seasonal change in probability of $(A)$ detecting 1 or more territorial pairs of golden eagles in the Diablo Range, California, with and without historical data available on locations of previously used nests and activity centers, and (B) misclassifying a site with successful reproduction as nonbreeding given the site was occupied in 2014. Vertical bar shows 95\% confidence interval.

\section{Probability of Occupancy and Successful Reproduction}

We detected at least one pair of golden eagles in 87 of the 133 sites surveyed, yielding a naïve occupancy probability (that is, uncorrected for imperfect detection) of $\widetilde{\psi}^{1}=0.65$. The model-averaged probability that a sample site was occupied by a territorial pair, $\widehat{\widehat{\psi}}^{1}$, was 0.67 $(95 \% \mathrm{CI}=0.53-0.78)$, which was only slightly larger than the naïve estimate owing to the overall high probability of detecting territorial pairs that were present. Nesting (incubating eagle or young present) at was evident at 20 sample sites; 5 pairs fledged 2 young each, 12 pairs fledged 1 young each, and 3 pairs failed in their nesting attempt during the incubation stage for unknown reasons (mean number of fledglings per successful nest $=1.1$, standard error $[\mathrm{SE}]=$ 0.14). Successful reproduction (nestlings or fledglings present) was detected at 17 of the 87 occupied sites, yielding a naïve probability of successful reproduction at an occupied site of $\tilde{\psi}^{2} \approx$ 0.20. The model-averaged probability that successful reproduction occurred in an occupied site, $\widehat{\bar{\psi}}^{2}$, was $0.30(95 \% \mathrm{CI}=0.12-0.57)$. The model-averaged, unconditional probability that a given sample unit was occupied with successful breeding, $\widehat{\bar{\psi}}_{\text {(breeding) }}$, was 0.20 (95\% CI $=0.08-$ 0.42), whereas the naïve estimate of the proportion of sites surveyed with successful reproduction was $\widetilde{\psi}^{1 * 2}=0.13$. Thus, the occurrence of territorial pairs that successfully produced young was underestimated by about one-third when the uncorrected, naïve estimate was used for inference. 
Models that incorporated the influence of spatial covariates on probability of occupancy and reproduction greatly outperformed models without these effects (table 2). Our overall top model included the additive and positive effects of grassland cover and mean terrain ruggedness on probability of occupancy (fig. 3). We also found support for a negative effect of scrub/shrub cover on the probability of successful reproduction $(\beta=-9.83,95 \% \mathrm{CI}=-19.67-0.02)$, but the precision of this relationship was poor, likely owing in part to the low number of sites with breeding $(n=17)$. Models that considered quadratic effects of vegetation cover on occupancy parameters were not competitive relative to models without these effects $\left(\triangle Q \mathrm{AIC}_{\mathrm{c}}>5.0\right)$.
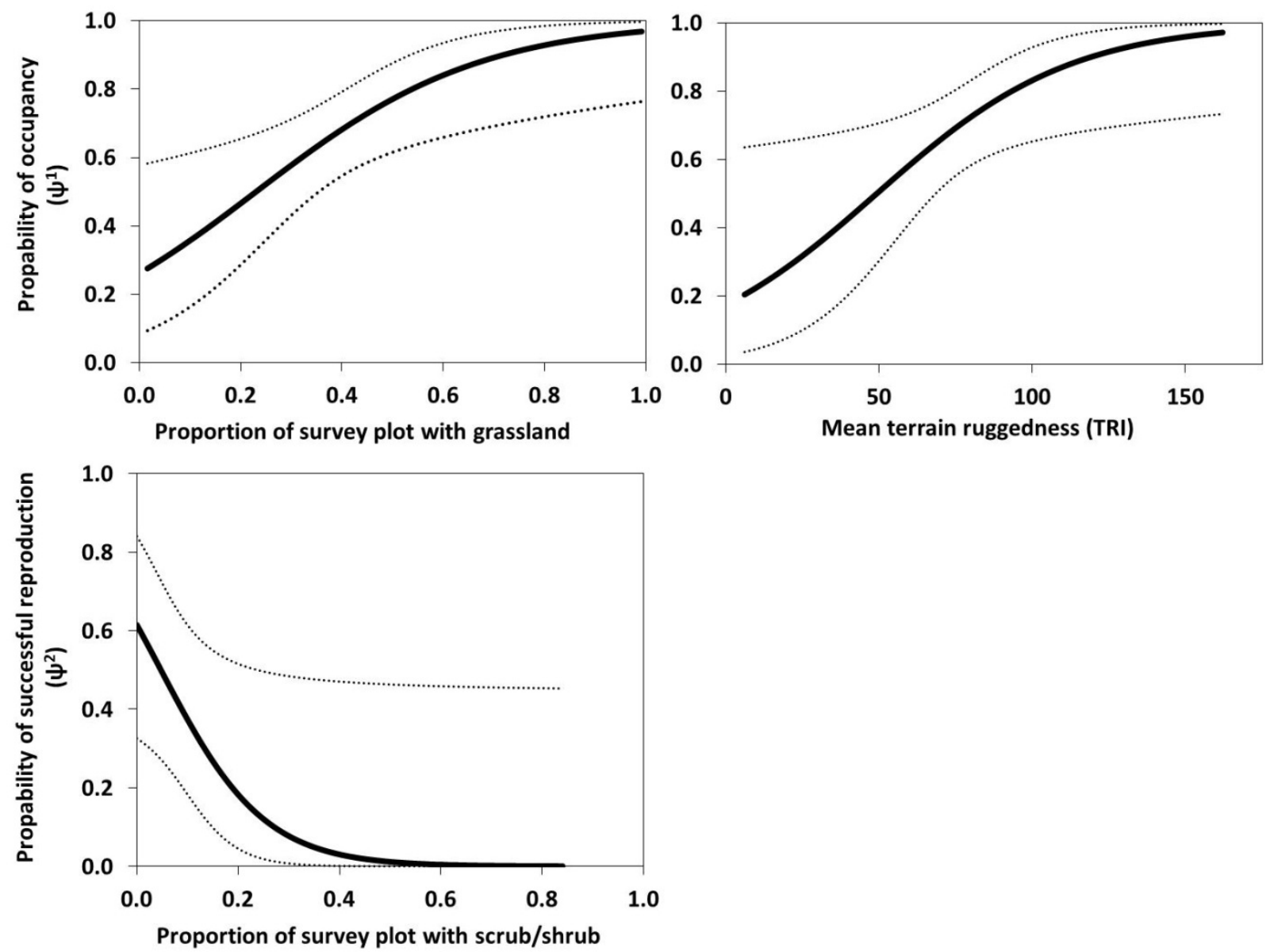

Figure 3. Graphs showing probabilities of occupancy $\left(\psi^{1}\right)$ and successful reproduction $\left(\psi^{2}\right)$ of territorial pairs of golden eagles as a function of vegetation cover and terrain ruggedness in the Diablo Range, California, 2014. Solid black lines represent predicted values estimated under the top multistate occupancy model $(\triangle Q A I C c=0.00$; table 2$)$; dotted lines represent $95 \%$ confidence intervals. 


\section{Total Area Occupied and Number of Territorial Pairs}

Using our best-fitting multistate occupancy model and the approach outlined by Rich and others (2013), we estimated that 388,217 ha (68.9 percent) of the 516,844-ha study area was occupied by territorial pairs of golden eagles in 2014. Thus, assuming an average territory size of $1,385 \mathrm{ha}$, the estimated total number of territorial pairs of golden eagles in the entire study area was 280 (bootstrap $\mathrm{SE}=12.2,95 \% \mathrm{CI}=256-305$ pairs of eagles).

\section{Discussion}

Three general findings characterized our investigation of detectability, occupancy, and reproduction of territorial pairs of golden eagles in the Diablo Range in 2014. First, the probability of detecting breeding golden eagles and their young during surveys was less than 1 and varied with time of the breeding season, as did the probability of correctly classifying a pair's breeding status. These two sources of uncertainty-imperfect detection and classification - led to a notable difference between the naïve estimate of the proportion of sites with successful reproduction (0.13) and our model-based estimate (0.20). Second, our multistate occupancy analysis provided strong support for non-random spatial distribution in occurrence and breeding success of territorial pairs of golden eagles in the broader landscapes surrounding APWRA. Spatial variation in these parameters was best explained by broad-scale differences among survey sites in primary vegetation types and terrain conditions. Third, the relatively high probability of landscape occupancy $(0.67)$ and number of territorial pairs we estimated to occur in the Diablo Range study area (about 280) supported the perception that the high density of breeding golden eagles observed near APWRA by Hunt and Hunt $(2006,2013)$ extends into much of the broader surrounding region of the Diablo Range.

Our results emphasize the importance of accounting for imperfect detection and spatial heterogeneity in broad-scale investigations of occupancy and reproduction of golden eagles. The analysis presented here was limited in that it was based on a single breeding season. Moreover, this study was conducted during a period of extreme drought conditions in central California, which could have influenced behavior and reproduction of golden eagles (Steenhof and others, 1997; McIntyre and Schmidt, 2012). Additional years of survey data are required to investigate spatial dynamics of occupancy and reproduction, to evaluate predictive performance of models, and to capture a broader range of environmental conditions affecting golden eagles in the region. Despite these limitations, our sampling design was highly effective in estimating and detecting variation in landscape occupancy and breeding success of golden eagles while accounting for variable and imperfect detection of adults and their young during surveys. The multistate occupancy study design offers a promising technique for monitoring the spatial distribution of occupancy and reproduction of golden eagles at broad spatial scales when alternative methods may be limited by logistics, accessibility, or budget constraints. 


\section{Detectability of Golden Eagles and Their Young}

The probability of detecting 1 or more territorial pairs of golden eagles during groundbased surveys of an occupied sample site (mean $=0.80$ over four survey occasions) was comparable to that estimated for golden eagles during aerial surveys of cliff nests $(0.68$; Booms and others, 2010) and during a combination of aerial- and ground-based surveys (about 0.90; Martin and others, 2009). Golden eagles are large, conspicuous birds with highly visible territorial displays, but our finding that detection probability during a single survey was less than 1 , regardless of breeding state, indicates that multiple surveys are required to reliably detect pairs of golden eagles that are present. In our study, detection probability was greatest during the early stages of breeding, when pairs were most heavily engaged in courtship behaviors and territorial displays that made them readily observable. Detection probability also increased when observers used historical data on previously used nest locations or activity centers to locate eagles during surveys. Golden eagles often re-use alternate nest structures within their territories (Kochert and others, 2012), so the ability to integrate historical data into our survey protocol and analysis of detection rates was a major advantage of our approach. Despite our predictions, we found only weak evidence that detection probability was negatively influenced by the amount of forest cover in a survey site. Our measure of forest cover, however, was coarse in that it did not account for finer-scale attributes of forest patches that could have influenced visibility of golden eagles and their young (for example, tree species, tree height, or canopy cover). Given the difficulties we experienced observing golden eagles and their young in heavily forested parts of the study area, we suspect that detection rates are more strongly influenced by forest conditions than what was supported by our analysis. Future analyses could examine this hypothesis by incorporating more detailed spatial covariates in modelling detection in forested areas.

The importance of accounting for imperfect detection of nests and young during groundbased surveys of golden eagles was highlighted by our analysis. Successful breeding by territorial pairs was correctly identified only about one-half the time when the naïve, uncorrected survey data were used. Correct classification probabilities at sample sites where young were produced were very low during surveys conducted during early stages of nestling development (0.09-0.53), but increased to near 1.0 later in the breeding season as young eagles began to fledge from their tree nests and became more visible to observers. These sources of uncertainty encountered during surveys led to a considerable difference between naïve $(0.13)$ and modelbased (0.24) estimates of the proportion of sites with successful reproduction. Our analysis was limited in that it was based on a single survey season with a low number of sites with successful breeding detected $(n=17)$. Nonetheless, these findings clearly illustrate the importance of appropriately accounting for uncertainty in detection and breeding classification of golden eagles. Given recent studies showing imperfect detection of cliff-nesting golden eagles inhabiting much more open landscapes than our study area (Booms and others, 2010), we suggest that estimation approaches such as those we used here be considered for future demographic analyses of golden eagles. 


\section{Spatial Pattern of Occupancy and Breeding Success}

Golden eagles were nonrandomly distributed in the study area, with occupancy being greatest in sample sites with relatively rugged terrain and greater amounts of open grassland habitats. Our analysis indicated a relatively high probability of landscape occupancy by pairs of golden eagles (0.67), but that areas with the greatest predicted occupancy potential $(>0.6)$ were patchily distributed. By projecting our occupancy model across the study area (fig. 4), we illustrated that the spatial pattern of pair occupancy and successful breeding was not uniform. Several studies have identified relationships between terrain conditions and foraging areas of golden eagles, and our results were consistent with these findings in that occupancy was positively associated with terrain ruggedness. Topography is an important component of the landscape that may interact with wind conditions and vegetation to influence how golden eagles use space (McLeod and others, 2002; Katzner and others, 2012). The coarse-scale spatial covariates we used to represent vegetation cover and terrain features likely missed many of the fine-scale features that influence occupancy and breeding success of golden eagles (for example, prey abundance), but the strong support for these effects in our analysis showed clear associations between landscape structure, distribution of territorial pairs, and reproductive success. This finding has important implications for conservation prioritization for golden eagles, as it highlights a potential linkage between landscape composition and population vital rates-a connection relevant to understanding fitness consequences of changes in site quality, source-sink dynamics, and other aspects of metapopulation dynamics (Pulliam, 1988; Runge and others, 2006). We emphasize that dynamic occupancy models that incorporate multiple years of data and focus on characterizing how rates of local colonization and extinction vary spatially and over time hold the best promise for understanding and predicting such connections (Yackulic and others, 2015).

Perhaps owing to the extreme drought conditions in central California in 2014, few territorial pairs were documented nesting in the study area, and even fewer successfully produced young. Our naïve estimate of the probability of successful breeding at an occupied survey site (0.20) was lower than that estimated from six previous annual reproduction surveys of golden eagles completed within $30 \mathrm{~km}$ of APWRA (range = 0.33-0.65; Hunt and Hunt, 2013). Predictions from our best-supported multistate occupancy model indicated a negative, albeit imprecise, association between proportion of scrubland vegetation cover at a site and breeding success. Large patches of scrubland, which dominated sites in the central part of the study area, included chaparral shrubs 2-5 m tall, tree shrubs, young trees in early successional state, and trees stunted from environmental conditions (National Oceanic and Atmospheric Administration, 2013). We posit that these conditions limit prey availability and foraging opportunities for golden eagles. It is also possible that prey abundance was reduced in these areas because of the severe drought conditions in 2014. In many areas, for example, golden eagles nest more often and produce more fledglings when their primary prey is abundant and weather conditions are favorable (Steenhof and others, 1997; Kochert and others, 2002; McIntyre and Schmidt, 2012). Our analysis was based on a single breeding season, and we used simplistic land-cover categories to demonstrate the ecological applications of our sampling method and estimation techniques. A more detailed analysis would include additional years of data and the refinement of spatial and climatic covariates. 

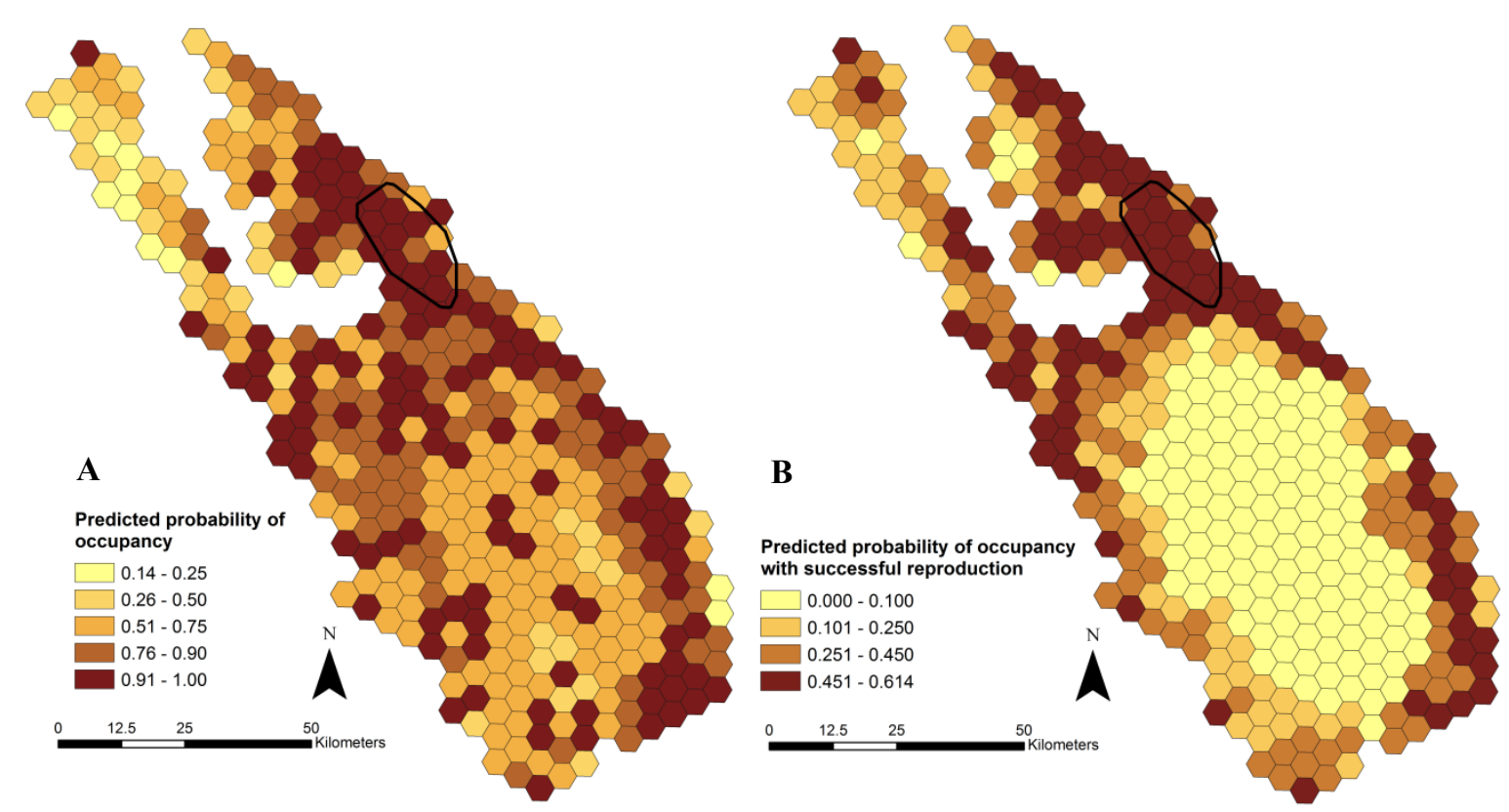

Figure 4. Maps showing estimated spatial pattern of (A) occupancy $\left(\psi^{1}\right)$, and (B) occupancy with successful reproduction ( $\psi_{\text {(breeding) }}$ ) for territorial pairs of golden eagles in the Diablo Range study area, California, 2014. We estimated predicted values under the top multistate occupancy model $(\triangle Q A I C c=$ 0.00; table 2). Altamont Pass Wind Resource Area also is shown (black polygon).

\section{Estimated Abundance of Territorial Pairs}

We documented a total of 138 territorial pairs of golden eagles during surveys completed in the 2014 breeding season, which represented about one-half of the estimated 280 pairs in the study area. The method we used to estimate the number of territorial pairs of golden eagles from occupancy data was based on three key assumptions that warrant careful consideration. The first assumption was that our estimate of mean territory size $(1,385 \mathrm{ha})$ was accurate. That estimate was based on the mean size of the core-use area estimated from adult golden eagles radiomarked in the study and on the sizes of previously studied, contiguous territories. The mean number of territorial pairs observed per 1,385-ha sample site (1.1 pairs) also did not deviate substantially from 1, which gave us further confidence that our sampling scale was appropriate for the study population. We found 1 or more pairs of eagles in 9 of 133 surveyed sites, however, and our estimate of total number of pairs did not account for 1 or more pairs per site. As a consequence, our estimate of the total number of pairs in the study area should be viewed as conservative. The second assumption was that there was minimal overlap among territories of adjacent pairs of golden eagles. We do not believe there was a major violation of this assumption because the relatively high density of breeding pairs in the study area likely resulted in minimal overlap among territorial boundaries. The third assumption was that unoccupied space between territories was minimal. Some spatial separation among territory boundaries was likely, particularly in parts of the study area with lower probability of occupancy (fig. 4). By not accounting for inter-territory buffer space within unoccupied habitats, the estimate of the number of pairs would have been positively biased. A possible approach to correct estimates of abundance for inter-territory space would be to allow territory size to vary spatially in accordance with site-specific conditions. 


\section{Applications for Monitoring and Conservation}

The development of wind-power and solar facilities is expected to increase dramatically in habitats occupied by golden eagles the Western United States. A key objective of conservation plans for golden eagles exposed to renewable energy development includes monitoring population trends so that regulatory officials can determine the appropriate number of permits to issue for take requests by renewable energy projects while maintaining the goal of a stable or increasing breeding population (U.S. Fish and Wildlife Service, 2013). The monitoring of changes in vital rates of a wide-ranging, long-lived species such as the golden eagle, however, is strongly limited by the cost and logistical challenges associated with implementing traditional sampling methods and mark-recapture studies at broad spatial scales. Our findings suggest that estimation of breeding state and associated detection probabilities, as defined by Nichols and others (2007) and MacKenzie and others (2009), may be an especially effective tool for identifying and monitoring spatial patterns of occupancy and reproduction of golden eagles exposed to renewable energy development. Under this framework, failure to detect young at a site does not necessarily indicate absence of successful reproduction, but instead admits the uncertainty associated with classifying the breeding state of a site. In our study, undetected nests and young during surveys led to a negative bias in determining breeding success at sites occupied by territorial pairs. The magnitude of this bias further suggested that estimates of fecundity and population trends derived from data collected during remote surveys of golden eagles also would be biased low. We base this conclusion on well-established sampling theory and repeatable modeling techniques that provide population estimates accompanied by measures of uncertainty. We have carefully described our sampling design, and the underlying assumptions of our models used to estimate occupancy, reproduction, and the number of territorial pairs occupying a given area, such that these assumptions can be critically evaluated by future work. Accordingly, we encourage the development of multi-season occupancy models that directly account for imperfect detection of breeding and nonbreeding golden eagles in estimates of occupancy and nesting success. Indeed, this adaptable approach promises a clearer understanding of the dynamic spatial mechanisms influencing populations of golden eagles (also see Martin and others, 2009).

Conservation policy often is aimed at managing landscape change, either through restoration, mitigation, or protection. Identifying linkages between landscapes, climate, and population vital rates, therefore, is a critical step in the development of effective conservation policy aimed at managing species sensitive to changes in human land use and climate (Lawler and others, 2008; Hole and others, 2011). This study provides quantitative information on spatial patterns of occupancy and reproduction of golden eagles near a large wind-energy facility during a period of extreme drought. Additional years of survey data are required to confirm good performance of the sampling design and to capture a broader range of environmental conditions that may influence breeding success of golden eagles in the region. We also note that the analysis presented here was focused on detections of territorial pairs of golden eagles, but that our surveys included all golden eagles (that is, juveniles, subadults, breeding and nonbreeding adults). Surveys focused solely on the territorial segment of golden eagle populations do not account for nonbreeding, floater individuals of a golden eagle population that can quickly replace breeder mortality and complicate estimates of population trends (Hunt, 2002; Hunt and Hunt, 2006. Future research could evaluate the estimation methods we present here in identifying spatial patterns of occurrence of the nonbreeding segment of golden eagle populations. 


\section{Acknowledgments}

This study was jointly funded by the U.S. Fish and Wildlife Service (Science Support Partnership, Region 8), the U.S. Geological Survey, the East Bay Regional Park District, and The Peregrine Fund, Inc. We are indebted to Step Wilson and Craig Himmelwright for their assistance with surveys of golden eagles. Colleen Lenihan and Eric Jepsen generously volunteered their assistance with survey logistics. We thank Doug Bell, Joe DiDonato, Harv Wilson, and their team of volunteers for providing logistical support and historical information on locations of golden eagles. Our work would not have been possible without support from the East Bay Regional Park District, California Department of Fish and Wildlife, California State Parks, San Francisco Water Department, Santa Clara County Parks, The Nature Conservancy, NextEra Energy, Inc., and the many other landowners that provided us with permission to access their lands to survey golden eagles. J.D. Nichols and 1 anonymous reviewer provided helpful comments that improved our manuscript.

\section{References Cited}

Bloom, P.H., and Clark, W.S., 2001, Molt and sequence of plumages of golden eagles and a technique for in-hand ageing: North American Bird Bander, v. 26, p,97-116.

Booms, T.L., Schempf, P.F., McCaffery, B.J., Lindberg, M.S., and Fuller, M.R., 2010, Detection probability of cliff-nesting raptors during helicopter and fixed-wing aircraft surveys in western Alaska: Journal of Raptor Research, v. 44, p. 175-187.

Burnham, K.P., and Anderson D.R., 2002, Model selection and multimodel inference-A practical information-theoretic approach (2d ed.): New York, Springer-Verlag.

Carrete, M., Sánchez-Zapata, J.A., and Calvo, J.F., 2000, Breeding densities and habitat attributes of golden eagles in southeastern Spain: Journal of Raptor Research v. 34, p. 48-52.

Driscoll, D., 2010, Protocol for golden eagle occupancy, reproduction, and prey population assessment. American Eagle Research Institute, Apache Junction, Arizona,. 55 p.

Hole, D.G., Huntley, B., Arinaitwe, J., Butchart, S.H.M., Collingham, Y.C., Fishpool, L.D.C., Pain, D.J., and Willis, S.G., 2011, Toward a management framework for network of protected areas in the face of climate change: Conservation Biology, v. 25, p. 305-315.

Hunt, T.L., and Hunt, W.G., 2013, Golden eagle territory occupancy and reproduction in the vicinity of the Altamont Pass Wind Energy Resource Area-2013 survey results: Oakland, California, Report to East Bay Regional Parks District.

Hunt, W.G., 2002, Golden eagles in a perilous landscape-Predicting the effects of mitigation for wind turbine blade-strike mortality: Sacramento, California, Consultant Report to California Energy Commission under contract P500-02-043F, Public Interest Energy Research, $72 \mathrm{p}$.

Hunt, W.G., and Hunt, T.L., 2006, The trend of golden eagle territory occupancy in the vicinity of the Altamont Pass Wind Resource Area-2005 survey: California Energy Commission, PIER Energy-Related Environmental Research. CEC-500-2006-256, 11 p.

Hunt, W.G., Jackman, R.E., Brown, T.L., and Culp, L., 1998, A population study of golden eagles in the Altamont Pass Wind Resource Area-Population trend analysis 1994-1997: Santa Cruz, California, University of California, Report to National Renewable Energy Laboratory, Subcontracts XAT-5-15174-01, XAT-6-16459-01 to the Predatory Bird Research Group. 
Hunt, W.G., Jackman, R.E., Brown, T.L., Driscoll, D.E., and Culp, L., 1996, A population study of golden eagles in the Altamont Pass Wind Resource Area-Second-year progress report: Santa Cruz, California, University of California, Report to National Renewable Energy Laboratory, Subcontracts XAT-5-15174-01 and XAT-6-16459-01 to the Predatory Bird Research Group.

Katzner, T.E., Brandes, D., Miller, T., Lanzone, M., Maisonneuve, C., Tremblay, J.A., Mulvihill, R., and Merovich, G.T., Jr., 2012, Topography drives migratory flight altitude of golden eagles: implications for on-shore wind energy development: Journal of Applied Ecology v. 49, p. $1178-1186$.

Kochert, M.N., and Steenhof, K., 2012, Frequency of nest use by golden eagles in southwestern Idaho: Journal of Raptor Research, v. 46, p. 239-247.

Kochert, M.N., Steenhof, K., McIntyre, C.L., and Craig, E.H., 2002, Golden eagle (Aquila chrysaetos), in Poole, A., and Gill, F. (eds.), The Birds of North America, no. 684, Philadelphia, The Birds of North America Inc., p. 1-44.

Lawler, J.J., Tear, T.H., Pyke, C., Shaw, M.R., Gonzalez, P., Kareiva, P., Hansen, L., Hannah, L., Klausmeyer, K., and Aldous, A., 2008, Resource management in a changing and uncertain climate: Frontiers in Ecology and the Environment, v. 8, p. 35-43.

MacKenzie, D.I., Nichols, J.D., Royle, J.A., Pollock, K.H., Bailey, L.A., and Hines, J.E., 2006, Occupancy estimation and modeling: San Diego, California, Academic Press.

MacKenzie, D.I., Nichols, J.D., Seamans, M.E., and Gutiérrez, R.J., 2009, Modeling species occurrence dynamics with multiple states and imperfect detection: Ecology, v. 90, p. 823-835.

Martin, J., McIntyre, C.L., Hines, J.E., Nichols, J.D., Schmutz, J.A., and MacCluskie, M.C., 2009, Dynamic multistate site occupancy models to evaluate hypotheses relevant to conservation of golden eagles in Denali National Park, Alaska: Biological Conservation v. 142 , p. 2,726-2,731.

Marzluff, J.M., Knick, S.T., Vekasy, M.S., Schueck, L.S., and Zarriello, T.J., 1997, Spatial use and habitat selection of golden eagles in southwestern Idaho: The Auk, v. 114, p. 673-687.

McIntyre, C.L., Collopy, M.W., Kidd, J.G., and Stickney, A.A., 2006, Characteristics of the landscape surrounding golden eagle nest sites in Denali National Park and Preserve, Alaska: Journal of Raptor Research, v. 40, p. 46-51.

McIntyre, C.L., and Schmidt, J.H., 2012, Ecological and environmental correlates of territory occupancy and breeding performance of migratory golden eagles Aquila chrysaetos in interior Alaska: Ibis, v. 154, p. 124-135.

McLeod, D.R.A., Whitfield, D.P., and McGrady, M.J., 2002, Improving prediction of golden eagle (Aquila chrysaetos) ranging in western Scotland using GIS and terrain modeling: Journal of Raptor Research, v. 36, p. 70-77.

Nichols, J.D., Hines, J.E., MacKenzie, D.I., Seamans, M.E., and Gutiérrez, R.J., 2007, Occupancy estimation and modeling with multiple states and state uncertainty: Ecology, v. 88, p. $1,395-1,400$.

National Oceanic and Atmospheric Administration, 2010, Coastal Change Analysis Program (CCAP) Regional Land Cover Database: Charleston, South Carolina, National Oceanic and Atmospheric Administration Coastal Services Center, accessed March 3, 2013, at www.csc.noaa.gov/landcover.

Noon, B.R., Bailey, L.L., Sisk, T.D., and McKelvey, K.S., 2012, Efficient species-level monitoring at the landscape scale: Conservation Biology, v. 26, p. 432-441. 
Pagel, J.E., Whittington, D.M., and Allen, G.T., 2010, Interim golden eagle inventory and monitoring protocols and other recommendations: Division of Migratory Bird Management, U.S. Fish and Wildlife Service.

Pulliam, H.R., 1988, Sources, sinks, and population regulation: American Naturalist, v. 132, p. 652-661.

Rich, L.N., Russell, R.E., Glenn, E.M., Mitchell, M.S., Gude, J.A., Podruzny, K.M., Sime, C.A., Laudon, K., Ausband, D.E., and Nichols, J.D., 2013, Estimating occupancy and predicting numbers of gray wolf packs in Montana using hunter surveys: Journal of Wildlife Management v. 77, p. 1,280-1,289.

Riley, S.J., DeGloria, S.D., and Elliot, R., 1999, A terrain ruggedness index that quantifies topographic heterogeneity: Intermountain Journal of Sciences, v. 5, p. 23-27.

Runge, J.P., Runge, M.C., and Nichols, J.D., 2006, The role of local populations within a landscape context: defining and classifying sources and sinks: American Naturalist, v. 167, p. 925-938.

Smallwood, K.S., and Thelander, C., 2008, Bird mortality in the Altamont Pass Wind Resource Area, California: Journal of Wildlife Management, v. 72, p. 215-223.

Steenhof, K., Kochert, M.N., and McDonald, T.L., 1997, Interactive effects of prey and weather on golden eagle reproduction: Journal of Animal Ecology, v. 66, p. 350-362.

Steenhof, K., and Newton, I., 2007, Assessing nesting success and productivity. in D.E. Bird and K.L. Bildstein (eds.), Raptor research and management techniques: Blaine, Washington, Hancock House Publishers, p. 181-192.

White, G.C., and Burnham, K.P., 1999, Program MARK: survival estimation from populations of marked animals: Bird Study, v. 46, p.120-139.

White, G.C., Burnham, K.P., and Anderson, D.R., 2001, Advanced features of program MARK, Wildlife, land, and people-Priorities for the $21^{\text {st }}$ century, in The Second International Wildlife Management Congress, Proceedings: Bethesda, Maryland, The Wildlife Society.

Wiens, J.D., Anthony, R.G., and Forsman, E.D., 2011, Barred owl occupancy surveys within the range of the northern spotted owl: Journal of Wildlife Management, v. 75, p. 531-538.

Yackulic, C.B., Nichols J.D., Reid, Janice, and Der, Ricky, 2015, To predict the niche, model colonization and extinction: Ecology, v. 96, no. 1, p. 16-23, http://dx.doi.org/10.1890/141361.1.

U.S. Fish and Wildlife Service, 2013, Eagle conservation plan guidance: module 1-Land-based wind energy, version 2: U.S. Department of the Interior, Division of Migratory Bird Management. 


\section{Appendix A. A priori Models Used to Characterize Variation in Detection, Occupancy, and Successful Reproduction of Golden Eagles in the Diablo Range, California, 2014}

[Model: Time effects modeled as constant (.) or varying with survey occasion $(t)$. Spatial covariates included sample site availability of historical data (HD); and proportion of sample site with grassland, forest, or scrub cover, and terrain ruggedness (TRI). We used the most general covariate structure for $\psi^{1}$ and $\psi^{2}$ when modeling probabilities of detection and classification]

\section{Model}

Description of model structure

Probability of detection $(p 1, p 2)$ and breeding classification ( $\delta$ )

$1 \quad \psi^{1}($ grassland + TRI $) \psi^{2}\left(\right.$ grassland $\left.^{2}\right)$ $p 1(t) p 2(t) \delta(t)$ - General model

$2 \psi^{1}($ grassland + TRI $) \psi^{2}\left(\right.$ grassland $\left.^{2}\right)$ $p 1() p .2(.) \delta(t)$

$3 \quad \psi^{1}($ grassland + TRI $) \psi^{2}\left(\right.$ grassland $\left.{ }^{2}\right) p(t)$ $\delta(t)$

$4 \quad \psi^{1}($ grassland + TRI $) \psi^{2}\left(\right.$ grassland $\left.^{2}\right) p($. $\delta(t)$

$5 \quad \psi^{1}($ grassland + TRI $) \psi^{2}\left(\right.$ grassland $\left.{ }^{2}\right)$ $p 1(t) p 2(t) \delta($.

$6 \quad \psi^{1}($ grassland + TRI $) \psi^{2}\left(\right.$ grassland $\left.^{2}\right)$ $p 1() p .2(.) \delta($.

$7 \quad \psi^{1}($ grassland + TRI $) \psi^{2}\left(\right.$ grassland $\left.^{2}\right) p(t)$ $\delta($.

$8 \quad \psi^{1}($ grassland + TRI $) \psi^{2}\left(\right.$ grassland $\left.^{2}\right) p($. $\delta($.$) - Null model$

$9 \quad \psi^{1}($ grassland + TRI $) \psi^{2}\left(\right.$ grassland $\left.{ }^{2}\right)$ $p$ (best structure from $1-8+\mathrm{HD}) \delta$ (best structure from 1-8)

$10 \quad \psi^{1}($ grassland + TRI $) \psi^{2}\left(\right.$ grassland $\left.^{2}\right)$ $p$ (best structure from $1-8+$ forest) $\delta$ (best structure from $1-8$ )
Detection varies by occupancy state and occasion, classification varies with occasion

Detection varies by occupancy state but not occasion, classification varies with occasion

Detection constant between states but varies with occasion, classification varies with occasion

Detection is constant between states and over occasions, classification varies with occasion

Detection varies by occupancy state and survey occasion, classification is constant

Detection varies by occupancy state but not occasion, classification is constant

Detection constant between states but varies with occasion, classification is constant

Detection is constant between states and over survey occasion, classifications is constant

Detection probability is dependent on availability of preexisting historical data on eagle locations

Detection probability is dependent on forest cover 
Probability of occupancy $\left(\psi^{1}\right)$ and breeding success $\left(\psi^{2}\right)$

$11 \psi^{1}$ (forest) $\psi^{2} p$ (best structure from $\left.1-10\right) \quad$ Occupancy is dependent on amount of forest
$\delta$ (best structure from $1-10)$

$12 \psi^{1}$ (forest 2$) \psi^{2} p$ (best structure from 1-10) Nonlinear, quadratic effect of amount of forest on occupancy $\delta$ (best structure from 1-10)

$13 \psi^{1}$ (grassland) $\psi^{2} p$ (best structure from $1-$ 10) $\delta$ (best structure from $1-10$ )

$14 \psi^{1}$ (grassland 2$) \psi^{2} p$ (best structure from $1-$ 10) $\delta$ (best structure from $1-10$ )

$15 \psi^{1}$ (scrub) $\psi^{2} p$ (best structure from $1-10$ ) $\delta$ (best structure from $1-10$ )

$16 \psi^{1}(\mathrm{TRI}) \psi^{2} p$ (best structure from $\left.1-10\right)$ $\delta$ (best structure from 1-10)

$17 \psi^{1}$ (forest + TRI) $\psi^{2} p$ (best structure from 1 - 10) $\delta$ (best structure from 1-10)

$18 \psi^{1}$ (grassland + TRI) $\psi^{2} p$ (best structure from $1-10) \delta$ (best structure from $1-$ 10)

$19 \psi^{1}(\mathrm{scrub}+\mathrm{TRI}) \psi^{2} p$ (best structure from $1-10) \delta$ (best structure from $1-10$ )

$20 \quad \psi^{1}$ (best structure from $\left.11-19\right) \psi^{2}$ (forest) $p$ (best structure from $1-10) \delta$ (best structure from 1-10)

$21 \psi^{1}$ (best structure from $\left.11-19\right) \psi^{2}$ (forest2) $p$ (best structure from $1-10) \delta$ (best structure from 1 - 10)

$22 \psi^{1}$ (best structure from 11-19) $\psi^{2}$ (grassland) $p$ (best structure from 110) $\delta$ (best structure from $1-10$ )

$23 \psi^{1}$ (best structure from 11-19) $\psi^{2}$ (grassland2) $p$ (best structure from $1-$ 10) $\delta$ (best structure from $1-10$ )

$24 \psi^{1}$ (best structure from $\left.11-19\right) \psi^{2}$ (scrub) $p$ (best structure from $1-10) \delta$ (best structure from 1-10)

Occupancy is dependent on amount of grassland

Nonlinear, quadratic effect of amount of grassland on occupancy

Occupancy is dependent on amount of scrub/shrub cover

Occupancy is dependent on terrain ruggedness (TRI)

Additive effects of forest and TRI on occupancy

Additive effects of grassland and TRI on occupancy

Additive effects of scrub/shrub cover and TRI on occupancy

Reproduction is dependent on amount of forest

Nonlinear, quadratic effect of amount of forest on reproduction

Reproduction is dependent on amount of grassland

Nonlinear, quadratic effect of amount of grassland on reproduction

Reproduction is dependent on amount of scrub/shrub cover 


\section{Appendix B. Multistate Occupancy Detection Histories of 133 Sample Sites Searched Repeatedly for Evidence of Occupancy and Successful Reproduction by Territorial Pairs of Golden Eagles in the Diablo Range, California, 2014}

Detection histories (formatted for program MARK) show whether a particular site was classified as unknown occupancy status (0), occupied by a territorial pair (1), or occupied by a territorial pair with young present (2) on each survey occasion. A “." denotes a missing observation (see details in Nichols and others, 2007).

\begin{tabular}{|c|c|c|c|}
\hline 1.1. 1; & .00 .1 & $11 . .1$ & 0.0 .1 \\
\hline 100. 1; & 00.01 ; & .1121 & 111. 1; \\
\hline .1 .01 & 10001 & 01111 ; & 110. 1; \\
\hline 11101 & 1.101 & 11011 & 111. 1; \\
\hline 10021 & 00.01 ; & 11111 & 111. 1; \\
\hline 10101 & 1001 & 112. 1; & 112. 1; \\
\hline 1.111 & .0001 & 11121 & 0000 1; \\
\hline 111. 1; & 100. 1; & .1101 & 000. 1; \\
\hline .10 .1 & 11.11 & $.0 . .1$ & 11101 \\
\hline 11101 & 100. 1; & 10011 & 110. 1; \\
\hline 111. 1; & 11011 & .0001 & 10221 ; \\
\hline 000. 1; & 110. 1; & 11121 & 12221 \\
\hline 1111 ; & 11001 & 10001 & 000. 1; \\
\hline 112. 1; & 01101 ; & 0101 ; & 000.1 \\
\hline 00.01 & 11201 & .12 .1 & 000. 1; \\
\hline 110. 1; & .0 .01 & 11221 & 01121 \\
\hline 1111 ; & $00 . .1$ & 11101 & 000. 1; \\
\hline .00 .1 & 00.01 ; & 11011 & 0000 1; \\
\hline 000.1 & .0 .01 & 11101 & 000. 1; \\
\hline 11111 & 1111 ; & .1 .11 & $11 . .1$ \\
\hline 10101 ; & 11001 ; & 00.01 & 11001 \\
\hline 11001 & 010. 1; & 01.01 & 000. 1; \\
\hline 000. 1; & 000. 1; & 1.221 & .1101 \\
\hline 000.1 & 01.01 & 122. 1; & 000. 1; \\
\hline 000.1 & 011. 1; & 00.01 & 000.1 \\
\hline 11101 & 10121 & $0 . .01$ & 000. 1; \\
\hline .1101 & 11111 & 000.1 & 000.1 \\
\hline 11011 & 01101 ; & 012. 1; & .00 .1 \\
\hline .1111 &. .111 & 000. 1; & 000.1 \\
\hline 11111 & 11011 & 000.1 & .00 .1 \\
\hline 000.1 &. .001 & $1 . .21$ & 011. 1; \\
\hline 110. 1; & .0101 & 110.1 : & \\
\hline 000. 1; & $10 . .1$ & 100. 1 & \\
\hline 1.0.1; & 000. 1; & 000.1 & \\
\hline
\end{tabular}



Publishing support provided by the U.S. Geological Survey Science Publishing Network, Tacoma Publishing Service Center

For more information concerning the research in this report, contact the Director, Forest and Rangeland Ecosystem Science Center U.S. Geological Survey

777 NW 9th St., Suite 400

Corvallis, Oregon 97330

http://fresc.usgs.gov/ 
